\title{
Occupation et exploitation temporaire des massifs de l'arrière-pays marseillais et toulonnais
}

\section{Sylvain Burri}

\section{(2) OpenEdition Journals}

Édition électronique

URL : http://journals.openedition.org/adlfi/6727

ISSN : 2114-0502

Éditeur

Ministère de la culture

Référence électronique

Sylvain Burri, « Occupation et exploitation temporaire des massifs de l'arrière-pays marseillais et toulonnais ", ADLFI. Archéologie de la France - Informations [En ligne], Provence-Alpes-Côte d'Azur, mis en ligne le 01 mars 2007, consulté le 03 mai 2019. URL : http://journals.openedition.org/adlfi/6727

Ce document a été généré automatiquement le 3 mai 2019.

(c) Ministère de la Culture et de la Communication, CNRS 


\title{
Occupation et exploitation temporaire des massifs de l'arrière- pays marseillais et toulonnais
}

\author{
Sylvain Burri
}

\author{
Identifiant de l'opération archéologique : 8291 \\ Date de l'opération : 2007 (PT) \\ Inventeur(s) : Burri Sylvain (AUT)
}

1 Cette prospection thématique avait pour but de recenser les structures d'habitat temporaire liées à la pratique d'un artisanat forestier du bois et de ses produits dérivés (charbon de bois, poix, huiles végétales, etc.).

2 Cette année plusieurs zones de test de prospection ont été choisies afin de sonder et d'évaluer le potentiel archéologique des différents massifs forestiers de l'arrière-pays marseillais et toulonnais. Ces zones d'essai sont : le massif de Conil et le plateau du Camps (communes de Ceyreste, de La Cadière, du Castellet (voir les deux notices consacrées au Castellet, Var.), du Beausset), le piémont sud du massif de la Sainte Baume (communes de Cuges-les-Pins et Gémenos), le massif du Gros Cerveau (communes de Sanary-sur-Mer, du Castellet, d'ollioules et d'évenos) et enfin le massif de l'ancienne Montanea de Cepet (communes de Six-Fours-les-Plages et de La Seyne-sur-Mer). Ce travail de prospection répond à une étude historique avec le dépouillement des fonds d'archives concernant l'exploitation et la gestion des ressources forestières au Moyen Âge.

3 Ces prospections ont visé le recensement des structures d'habitats temporaires ainsi que des structures artisanales (charbonnières, fours à chaux, fours à poix, fours à cade, etc.) souvent non datables en l'absence de mobilier archéologique associé. Cependant, la majorité des sites sont rattachables à l'époque moderne et contemporaine soit par leur bon état de conservation soit, quand on a de la chance, par du mobilier céramique. Trois sites ont livré du mobilier céramique médiéval (marmites et couvercles en pâte grise 
d'Ollières; jarres à cordons digités de catégorie B3 médiévaux). Deux indices de fréquentation protohistorique ont été repérés. Tous les autres vestiges sont modernes et contemporains.

4 On ne peut tirer de conclusions de cette première campagne de prospection dont l'objectif, je le rappelle, était d'évaluer le potentiel de certains secteurs forestiers en amont d'un véritable travail de prospection systématique mais surtout du fait du problème épineux de la visibilité des vestiges en milieu forestier et de garrigue.

INDEX

Index chronologique : Moyen Âge*, Moyen Âge, Protohistoire, Temps Modernes operation Prospection thématique (PRT)

\section{AUTEURS}

SYLVAIN BURRI

AUT 